\title{
A química no Vestibular Fuvest (1980-2018)
}

PAULO ALVES PORTO ${ }^{I}$

\section{Introdução}

$\mathrm{N}$

ESTE ARTIGO, procuramos analisar o programa de química do Vestibular Fuvest, que seleciona anualmente os candidatos ao ingresso na Universidade de São Paulo, por entendê-lo como um instrumento de política pública e, como tal, como um dos fatores a influenciar o currículo de química nas escolas de Ensino Médio. Evidentemente, não se trata de supervalorizar o programa do vestibular como determinante do que se realiza nas salas de aula, visto ser o currículo uma complexa construção social (Goodson, 1997). Porém, é possível considerá-lo como um dos componentes dessa construção, influenciando a seleção de conteúdos e as formas de abordá-los. Sendo um instrumento de seleção fundamentado na avaliação da aprendizagem escolar, o vestibular pode ser incluído entre os "testes de rendimento" sobre os quais Sousa (2003, p.187-8) observa:

A avaliação... tende a imprimir uma lógica e dinâmica organizacional nos sistemas de ensino... Quanto ao currículo, destaca-se sua possível conformação aos testes de rendimento aplicados aos alunos, que tendem a ser vistos como os delimitadores do conhecimento que "tem valor", entendido o conhecimento como o conjunto de informações a serem assimiladas pelos alunos e passíveis de testagem.

Além disso, procuramos também relacionar o programa de química do Vestibular Fuvest com outros instrumentos de políticas públicas, de âmbitos estadual e federal. Sua articulação nesse contexto potencializa sua possível influência curricular, justificando a escolha da temática para estudo.

Ao abordar o programa de uma disciplina específica, voltada para o exame de seleção para ingresso na Universidade, nossa análise se volta para aspectos epistemológicos que são peculiares a essa disciplina. Um dos aspectos distintivos da química se relaciona ao papel desempenhado pelos modelos. Tanto a estrutura como a prática da química envolvem, de maneira marcante, a presença de modelos, com os quais os químicos procuram explicar os fenômenos e também planejam experimentos (Tomasi, 1999; Trindle, 1984). Nesse contexto, o modelo cinético de partículas encontra muitas aplicações. Isso se relaciona ao fato de que a química se caracteriza por se estruturar sobre dois níveis ontológicos: o macroscópico, das substâncias que se apresentam aos nossos sentidos, e o submicroscópico, das partículas como átomos, moléculas e íons (Talanquer, 2011; 
Gilbert; Treagust, 2010). Para explicar os fenômenos observados no nível macroscópico, os químicos criam construtos teóricos e linguísticos para representar o nível submicroscópico e as relações entre os dois níveis (Souza, 2012). Por esse motivo, um dos objetivos do ensino de Química tem sido propiciar que os estudantes compreendam a natureza e o papel dos modelos em química, bem como se tornem capazes de utilizá-los para a compreensão dos fenômenos químicos. Justi (2010, p.218) argumenta que os estudantes

[...] devem desenvolver habilidades de transitar entre diferentes modos de representação e compreender as vantagens e limitações de cada um deles em contextos diferentes. Isso está claramente relacionado com o desenvolvimento da capacidade de visualização. Os professores devem lidar com esse aspecto por meio do ensino direto ou de abordagens indiretas (nas quais os estudantes usam/produzem modelos a partir de diferentes modos de representação, percebendo, assim, as vantagens e limitações de cada um deles).

Por outro lado, a química não se limita a identificar e caracterizar as partículas do mundo submicroscópico. Fundamentalmente, a química se ocupa das relações entre elas, ou seja, de suas interações e das transformações que daí podem resultar. Assim, outro aspecto característico da química é sua natureza relacional, que perpassa seus conceitos, métodos, esquemas de classificação e linguagem (Bernal; Daza, 2010). Além disso, o caráter fortemente experimental (Chamizo, 2013; Schummer, 1997) e sua presença quase ubíqua em aplicações no cotidiano e no sistema produtivo (Hoffmann, 2007; Knight, 1992) são atributos da química com presença destacada também no discurso dos educadores da área (Silva et al., 2010; Bennett; Holman, 2002).

Tendo isso em vista, interessa-nos investigar como se manifestam alguns aspectos epistemológicos selecionados, característicos do conhecimento químico, nos programas e nas questões dos exames vestibulares da Fuvest no período compreendido entre 1980 e 2018 . Este estudo se volta para os critérios analíticos ou relacionais que orientam a seleção e organização dos conteúdos; as relações sugeridas entre os níveis ontológicos, macroscópico e submicroscópico; o uso de modelos de partículas para explicação dessas relações; a experimentação e a contextualização do conhecimento químico. Partimos da premissa que, dada a centralidade desses aspectos no âmbito da química e de seu ensino, é possível identificá-los nos programas e provas de química do vestibular. Dessa forma, buscamos delinear uma evolução temporal da abordagem desses aspectos no corpus analisado, a qual pode contribuir para reflexões de educadores em química a respeito do ensino e da avaliação da aprendizagem dessa disciplina escolar.

\section{Aspectos metodológicos}

O corpus de análise foi constituído pelos programas de química do Vestibular Fuvest de 1980 a 2018, e pelas provas de química da primeira e da segunda fases, de 1977 a 2018. Os programas foram obtidos no acervo disponibilizado 
no site da Fuvest, ${ }^{1}$ no qual não constam apenas os programas dos vestibulares dos anos 1977 a 1979, que por esse motivo não puderam ser incluídos na presente análise. Nesse mesmo acervo virtual estão disponíveis as provas dos vestibulares de 1997 a 2018 , em acesso aberto. As provas de química não disponíveis no site da Fuvest (de 1977 a 1996) foram obtidas no site sotaodaquimica, ${ }^{2}$ que se constitui em um repositório de vestibulares de química de várias instituições (como Unicamp, ITA, Enem), além de outras informações sobre química para vestibulandos. Esse material foi reunido por uma professora que se apresenta apenas como "Sonia", não havendo outras informações sobre a responsável pelo site.

Os programas disponíveis foram comparados ano a ano, tendo sido possível caracterizar seis programas diferentes ao longo do tempo. Tais programas foram, em seguida, analisados com respeito a aspectos epistemológicos característicos da química, referidos na Introdução, e também critérios de natureza didática, a saber: seleção e organização de conteúdos guiadas por critérios analíticos ou relacionais; inserção e retirada de conteúdos de um programa para outro; organização relativa de conteúdos referentes aos níveis macroscópico e submicroscópico; relação com diretrizes curriculares estaduais e federais.

Paralelamente, a análise das provas foi feita buscando a identificação de questões que abordassem a representação de modelos de partículas, a fim de caracterizar que tipos de habilidades e conhecimentos foram avaliados ao longo do tempo a respeito de modelos em química. Também se procurou situar a experimentação e contextualização do conhecimento químico, presentes em questões selecionadas, em relação às tendências apontadas nos diferentes programas. Não se incluiu entre os objetivos da presente pesquisa fazer um levantamento quantitativo nem catalogação de conteúdos ou habilidades avaliados nas questões dos vestibulares; nosso olhar para as questões foi qualitativo, orientado pelos referenciais escolhidos, buscando situá-las como manifestações de diferentes aspectos dos programas e das tendências curriculares de cada período.

\section{Resultados e discussão}

Analisando os programas dos vestibulares Fuvest no período compreendido entre 1980 e 2018, observamos a existência de seis programas diferentes, aqui identificados com os números 1 a 6 . Existem, porém, muito poucas diferenças entre os programas 1 e 2 , entre os programas 3 e 4 e entre os programas 5 e 6. Assim sendo, optamos por agrupá-los, dois a dois, em periodos (identificados com os algarismos romanos I, II e III), que representam diferentes tendências para o programa de química (Tabela 1). 
Tabela 1 - Classificação dos programas de química do Vestibular Fuvest em períodos

\begin{tabular}{|c|c|c|c|}
\hline \multirow{2}{*}{ Períodos } & Programas & Vigência & Duração \\
\hline \multirow{2}{*}{ I } & 1 & $1980-1988$ & 9 anos \\
\cline { 2 - 4 } & 2 & $1989-1990$ & 2 anos \\
\hline \multirow{2}{*}{ II } & 3 & 1991 & 1 ano \\
\cline { 2 - 4 } & 4 & $1992-2001$ & 10 anos \\
\hline \multirow{2}{*}{ III } & 5 & 2002 & 1 ano \\
\cline { 2 - 4 } & 6 & $2003-2018$ & 16 anos \\
\hline
\end{tabular}

Fonte: Elaborado pelo autor.

Pode-se observar que, ao longo de 39 anos, houve poucos momentos de modificações significativas no programa de química do Vestibular Fuvest. O primeiro período se estendeu por 11 anos; o segundo, por outros 11; o terceiro período, que inclui o programa atual, já dura 17 anos. A seguir, caracterizamos e comentamos cada período, destacando as modificações mais expressivas em cada programa, incluindo questões que ilustram tendências dos vestibulares.

\section{Periodo I, Programa 1 (1980-1988)}

Nos primeiros anos do Vestibular Fuvest, o programa de química se caracterizou por seguir o modelo da racionalidade técnica, focalizando o conhecimento científico por si mesmo. O programa incluía tópicos que podem ser considerados como avançados em termos da complexidade dos conceitos e teorias envolvidos, tais como o modelo orbital para o átomo, hibridação e entropia. Outra característica do período é a apresentação da química descritiva (que abrange a exposição de ocorrência, propriedades físicas e químicas de substâncias e materiais, bem como suas aplicações - estando, portanto, mais associada a aspectos macroscópicos e ao sistema produtivo) como um tópico separado dos itens "teóricos". Tal organização não favorece a integração dos conhecimentos, tampouco sua contextualização.

Nesse período, o programa esteve estruturado em dezessete itens principais (cada qual detalhado em subitens, não reproduzidos aqui), cujos descritores são listados a seguir:

1 - Atividade científica;

2 - Substâncias puras;

3 - Estudo geral dos gases;

4 - Estudo geral dos líquidos e sólidos;

5 - Estrutura dos átomos;

6 - Tabela periódica;

7 - Ligação química;

8 - Reações químicas; 
9 - Cinética química;

10 - Energia nas reações químicas;

11 - Reações reversíveis - aspectos gerais;

12 - Reações reversíveis - ácidos e bases;

13 - Reações reversíveis em sistemas heterogêneos;

14 - Óxido-redução;

15 - Química descritiva;

16 - Compostos de carbono;

17 - Principais funções orgânicas.

Observa-se uma abordagem "analítica” para a organização dos conteúdos nesse programa: os primeiros itens referem-se à caracterização de substâncias, de gases, de estrutura atômica e das ligações químicas, antecedendo os aspectos relacionais da química que constituem seu cerne (Tontini, 2004; Schummer, 1998), isto é, todos os itens relativos a reações químicas.

A contextualização estava praticamente ausente das questões dos primeiros vestibulares da Fuvest. Apresentamos como exemplo duas questões da prova de 1977, uma da primeira e uma da segunda fase, que requeriam a simples memorização de informações sobre o modelo atômico orbital:

Em um átomo, quantos elétrons podem ocupar o orbital p representado na figura?

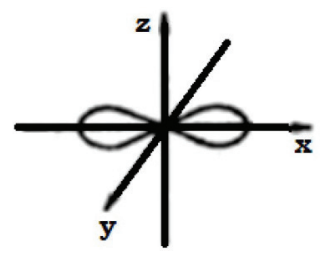

a) 2 ; b) 3 ;c) 4 ; d) 5 ; e) 6 .

Questão 05. Que tipos de ligação "sigma" possui a molécula $\mathrm{CH}_{3} \mathrm{Cl}$ ?

Nesse período, as raras vezes em que alguma referência externa ao contexto da própria ciência era feita tinham caráter apenas de curiosidade ou ilustração, como na questão a seguir, da primeira fase de 1978:

61. Bolinhas de naftalina ao serem colocadas em armários, com o decorrer do tempo, diminuem de tamanho. A causa desse comportamento deve-se ao fenômeno de

a) condensação ; b) congelação ; c) fusão ; d) sublimação ; e) liquefação.

O mesmo conhecimento foi avaliado na segunda fase do vestibular de 1985, com pouca variação:

Questão 05 . Bolinhas de naftalina são usadas no combate às traças.

a) Qual é o constituinte químico da naftalina?

b) Por que a bolinha de naftalina diminui de tamanho com o passar do tempo? 
Observa-se, ao longo desse primeiro período, um aumento gradual na frequência com que esse tipo de contextualização aparece nas questões de química. $\mathrm{Na}$ segunda fase do vestibular de 1987, uma questão proposta aos candidatos da "área de humanas" exemplifica a contextualização entendida como estudo científico de fenômenos do cotidiano - ainda que a situação apresentada no item b possa ser considerada, pelos padrões atuais, como inadequada para um cenário educacional:

Questão 16. Explique por que:

a) os alimentos cozinham mais rapidamente nas "panelas de pressão";

b) o cigarro aceso é consumido mais rapidamente no momento em que se dá a "tragada".

O item 1 dos programas desse período, "Atividade científica", incluía entre seus subitens a "Interpretação de modelos". Embora houvesse essa referência explícita no programa, as provas desse período pouco exploraram a manipulação visual de modelos de partículas para representar átomos e moléculas. Encontramos apenas uma questão em que se apresenta explicitamente um modelo concreto para representar partículas - ainda que não fosse por meio de um desenho - na segunda fase do vestibular de 1981:

Questão 02. São propriedades de qualquer substância no estado gasoso:

I - ocupar toda a capacidade do recipiente que a contém.

II - apresentar densidade bastante inferior à do líquido obtido pela sua condensação.

Para ilustrar essas propriedades, utilizou-se um liquidificador em cujo copo foram colocadas algumas esferas pequenas, leves e inquebráveis.

Explique como esse modelo pode ilustrar as propriedades I e II.

Observa-se que essa questão permite avaliar habilidades cognitivas de ordem superior, exigindo a visualização do modelo descrito e a tradução do modelo concreto como um análogo das partículas submicroscópicas. A explicação solicitada refere-se, porém, a propriedades físicas, e não químicas, das substâncias.

\section{Periodo I, Programa 2 (1989-1990)}

A estrutura em dezessete itens principais foi mantida no programa, com os mesmos descritores da versão anterior. Foram retirados, porém, os tópicos mais avançados (modelo orbital, hibridação, entropia), bem como radioatividade. O único acréscimo é uma isolada menção a "associação ao cotidiano" do tópico "estado coloidal", contrastando com o restante do programa, em que a relação com o cotidiano não é explicitada. Pode-se considerar, assim, que este programa constitui um único período em conjunto com o programa anterior, dada a continuidade entre eles.

Com relação ao uso explícito de modelos de partículas, encontramos uma questão na segunda fase do vestibular de $1990 \mathrm{em}$ que isso ocorre: 
Para comparação, transcrevemos também um trecho da referida Proposta Curricular, que deixa claro como esta serviu de base para o texto citado acima:

[...] o ensino de Química deverá visar à aprendizagem dos conceitos, princípios, teorias e leis desta ciência; à compreensão da natureza e processo de produção desse conhecimento, bem como a análise crítica de sua aplicação na sociedade... Propomos, assim, os seguintes princípios orientadores...

1 A experimentação...

2 A História da Ciência...

3 O cotidiano... (São Paulo, 1986, p.9-11)

A partir de 1991, o programa ganhou nova organização dos tópicos, valorizando a integração entre os níveis ontológicos macroscópico e submicroscópico da matéria. A ênfase do texto introdutório ao programa de química recaiu especialmente sobre a compreensão da ciência, ainda que houvesse menção às interações ciência-sociedade. Ao delinear o perfil desejado para o candidato, o texto afirmava: "considera-se importante que o aluno demonstre ser capaz de observar e descrever fenômenos, [e] formular modelos explicativos para os mesmos...". Observa-se o destaque para o processo de modelagem, que possibilita a construção de "pontes" entre o nível macroscópico e o nível submicroscópico da matéria.

O final do texto introdutório fazia referência a como a química orgânica seria abordada nas provas; as características delineadas em seguida sugerem, porém, que seriam comuns a todas as questões:

No tocante à Química Orgânica, o estudante deve ter a capacidade de reconhecer as diferentes classes de compostos (funções). Não se exige memorização pura e simples de métodos de obtenção e reações características. As Comissões de Seleção formularão questões fornecendo os dados necessários sem enfatizar memorização, avaliando a capacidade do estudante manipular informações. Espera-se a compreensão de relações entre grandezas e não a retenção mnemônica de equações específicas.

No ano seguinte, essa parte do texto foi reescrita, com a omissão do trecho que menciona a não exigência de "memorização pura e simples". Possivelmente, a intenção aqui foi de evitar mal-entendidos: afinal, alguma memorização é necessária, ainda que a intenção principal seja avaliar a compreensão.

Com a reformulação do programa, os conteúdos receberam uma nova organização, sendo estruturados agora em apenas sete itens principais (detalhados em subitens não reproduzidos aqui), cujos descritores são os seguintes:

1 - Transformações químicas;

2 - Utilização e propriedades dos materiais: aspectos científicos, tecnológicos e econômicos dos materiais;

3 - A água na Natureza;

4 - Dinâmica das transformações químicas;

5 - Energia nas transformações químicas; 
6 - Transformações nucleares naturais e artificiais;

7 - Estudo dos compostos de carbono.

Essa nova organização, ao colocar o descritor “Transformações químicas” em primeiro lugar, apontava para a substituição da abordagem "analítica” anterior pela valorização dos aspectos relacionais. Os subitens que detalham esse item também sugerem uma sequência para sua abordagem didática: os aspectos macroscópicos (evidências de transformação química, leis ponderais) precedem os aspectos submicroscópicos (teoria atômica, natureza elétrica da matéria). Essa sequência já estava presente no material didático elaborado pelo Grupo de Pesquisa em Educação Química (GEPEQ) sediado no Instituto de Química da USP, e que iniciara suas atividades em 1984. Esse material viria a dar origem ao livro didático Interações e Transformações - Química para o $2^{\circ}$ Grau, cuja primeira edição é de 1993. O projeto que levou à elaboração desse livro se fundamentava sobre teorias de aprendizagem de Piaget e de Ausubel, conforme explicado pelos autores em artigo publicado em 1992 (Bosquilha et al., 1992). Nesse artigo, os autores escreveram:

Além de proporcionar o desenvolvimento das operações lógico-empíricas de classificação, seriação e correspondência, o Projeto "Interações e Transformações - Química para o $2^{\circ}$. Grau” visa proporcionar ao aluno uma passagem gradativa do nível qualitativo para o nível quantitativo dos conceitos que já envolvem certo formalismo matemático. [...] [C]abe ressaltar que as interpretações dos fenômenos a nível microscópico, ou seja, a nível de comportamento de átomos e moléculas, que necessitam abstração, são precedidas de observações e análises de fenômenos a nível macroscópico, o que possibilita ao aluno o relacionamento entre fatos e teorias. (Bosquilha et al., 1992, p.358)

A ordem em que os conteúdos são apresentados no item "Transformações Químicas" no programa do vestibular Fuvest 1991 corresponde ao que seria uma organização curricular de acordo com esses princípios.

Observa-se que retornava ao programa de química, após dois anos de ausência, o tópico de "radioatividade", incluindo "histórico da radioatividade", bem como "problemas ambientais decorrentes" de seu emprego, subordinados ao item 6. Outro aspecto que chama a atenção nesse programa é a inserção de muitas menções a "aplicações práticas no cotidiano e no sistema produtivo", explicitamente associadas aos seguintes conteúdos: ácidos, bases e sais; efeitos do soluto nas propriedades da água (i.e., propriedades coligativas); estado coloidal; velocidade das transformações químicas; equilíbrio químico; transformações químicas e energia térmica; transformações químicas e energia elétrica; transformações nucleares. Ou seja, havia a preocupação de que os conceitos fundamentais da química fossem contextualizados - ainda que a forma de apresentação dos conteúdos no programa pudesse sugerir uma função apenas motivacional ou de aquisição de conhecimento de fatos e processos para essa contextualização. 


\section{Periodo II, Programa 4 (1992-2001)}

Nesse período, o texto introdutório ao programa de química foi ligeiramente ampliado em relação à versão de 1991, fornecendo detalhes complementares sobre alguns aspectos. O novo texto explicitava que "Os modelos atômicos deverão restringir-se apenas aos clássicos, não incluindo, desta maneira, $\mathrm{o}$ modelo orbital". Trata-se de um reconhecimento de que a química, no Ensino Médio, pode ser abordada por meio de modelos atômicos mais simples, não havendo a necessidade de fazer referência a teorias mais complexas que caracterizam os modelos atômicos contemporâneos.

Outro acréscimo ao texto introdutório é um comentário ao papel didático da tabela periódica dos elementos químicos: "A Tabela Periódica deve ser entendida como uma sistematização das propriedades físicas e químicas dos elementos e deste modo seu uso estará presente ao longo de todo o programa". Esse comentário contém uma clara recomendação de que a tabela periódica não é uma lista de nomes, símbolos e valores numéricos que devem ser memorizados, mas um material de consulta que deve acompanhar todo o estudo da química. Como orientação curricular, essa observação é de fundamental relevância.

Curiosamente, foram retirados do programa os subitens que explicitavam "ligação iônica", "ligação covalente", "polaridade", "forças intermoleculares", bem como, no subitem "ácidos, bases e sais", o tópico "propriedades, comportamento frente a indicadores, reações com metais". Provavelmente, os elaboradores do programa entenderam que, ao incluir subitens como "metais", "substâncias iônicas" e "substâncias covalentes", os respectivos tipos de ligação química envolvidos estariam implícitos.

As mudanças no programa, ocorridas em 1991, começaram a se fazer sentir mais claramente nas questões das provas a partir do ano seguinte. Embora os conhecimentos avaliados na prova de 1992 não sejam muito diferentes daqueles do ano anterior, a preocupação em relacionar os conteúdos de química com o cotidiano e o sistema produtivo é visível nos enunciados. Das dez questões de química da primeira fase de 1992, oito fazem referência a algum aspecto do cotidiano ("bronze, gelo seco e diamante"; "mineral presente nos ossos e nos dentes"; "água de uso doméstico"; "aromatizante que tem o odor de rosas"; "paredes pintadas com cal extinta"; "moedas feitas com ligas de cobre"; "vinagre"; "sacos plásticos, capas de chuva, tomadas elétricas"). A partir de 1993, a mudança no perfil da prova de química se torna mais perceptível. Os enunciados curtos e diretos, característicos dos primeiros anos da Fuvest, se tornam mais longos, fornecendo contextos mais detalhados. Exemplo dessa tendência é o primeiro dos testes de química apresentado aos candidatos em 1993:

Holanda quer deixar de ser um País Baixo

Da "Reuter"

Cientistas estão pesquisando a viabilidade de se elevar o litoral holandês que é muito baixo e há séculos vem sendo ameaçado por enchentes - atra- 
vés da injeção de substâncias químicas na terra.

Os pesquisadores acreditam poder elevar o litoral injetando ácido sulfúrico numa camada de rocha calcárea $1,5 \mathrm{~km}$ abaixo da superfície. A reação química resultante produziria gipsita, que ocupa o dobro do espaço do calcáreo e que empurraria a superfície terrestre para cima. (Notícia publicada na Folha de S. Paulo, outubro de 1992)

Sabendo que a gipsita é $\mathrm{CaSO}_{4}$ hidratado e que o calcáreo é $\mathrm{CaCO}_{3}$, a reação citada produz também

a) $\mathrm{H}_{2} \mathrm{~S}$; b) $\mathrm{CO}_{2}$; c) $\mathrm{CH}_{4}$; d) $\mathrm{SO}_{3}$; e) $\mathrm{NH}_{3}$

O recurso a representações gráficas para modelos de partículas não é muito utilizado nas questões propostas nos vestibulares desse período, mas sua ocorrência é digna de nota. Nas duas questões apresentadas a seguir, os modelos de partículas são utilizados em representações que se referem a transformações químicas. A primeira é do vestibular de 1997, e a segunda, do vestibular de 2000:

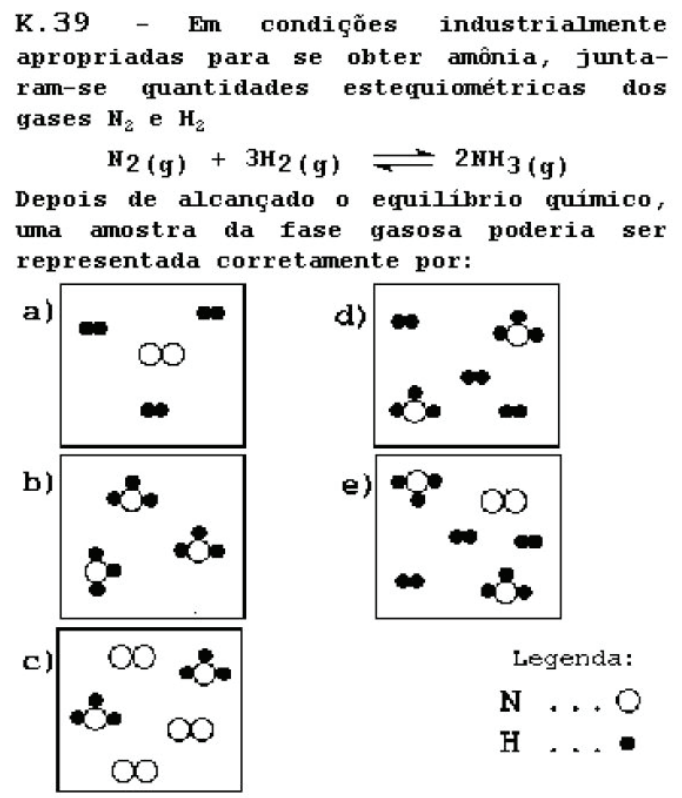

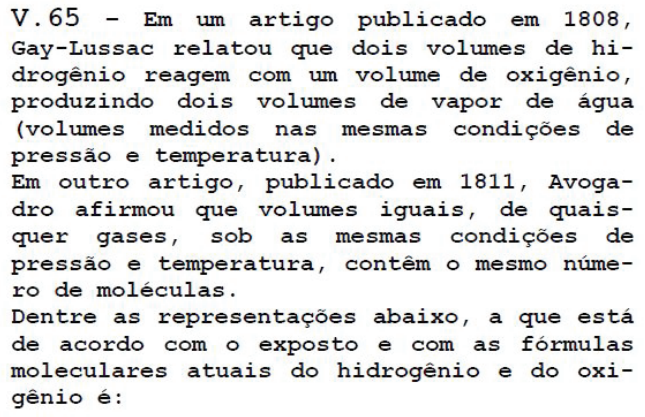

a)

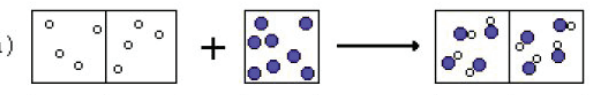

b)

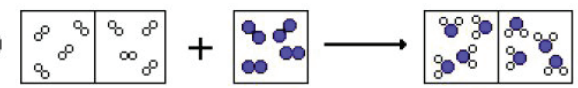

C) \begin{tabular}{|c|cc|}
\hline 8 & $\infty$ & 8 \\
$\infty$ & $\infty$ & $0^{\circ}$ \\
\hline
\end{tabular}
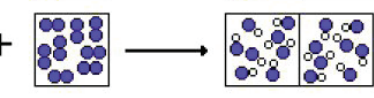

d) $\therefore \circ{ }^{\circ} \because$

$\because$

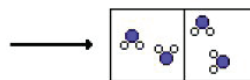

e)

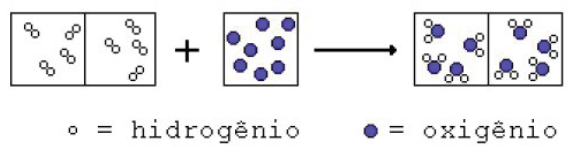

A questão de 1997 permite avaliar um aspecto fundamental do conceito de equilíbrio químico, que é a coexistência de reagentes e produtos no sistema após o estabelecimento do equilíbrio. O reconhecimento desse fato seria um indício importante da compreensão do conceito de equilíbrio - ainda que, por motivos óbvios, o desenho não permita avaliar outro aspecto essencial do conceito, que é seu caráter dinâmico. A questão de 2000 requer a manipulação do modelo, mas exige menos em termos cognitivos: essencialmente, requer a memorização das fórmulas moleculares do gás hidrogênio, do gás oxigênio e da água, a fim de identificar a representação que corresponde às fórmulas atuais. 


\section{Periodo III, Programa 5 (2002)}

O texto introdutório ao programa de química para o ano de 2002 foi novamente ampliado, recebendo alguns acréscimos explicativos e um detalhamento maior para alguns aspectos. Embora boa parte do texto anterior seja mantida, o novo parágrafo inicial desloca sua ênfase para a formação cidadã do estudante do Ensino Médio:

A Química exerce um relevante papel no desenvolvimento científico, tecnológico, econômico e social do mundo moderno. Neste sentido, é de fundamental importância que o estudante do Ensino Médio compreenda as transformações químicas que ocorrem no mundo físico de maneira a poder avaliar criticamente fatos do cotidiano e informações recebidas por diversas fontes de divulgação do conhecimento, tornando-se capaz de tomar decisões enquanto indivíduo e cidadão.

Assim, as diversas menções a "aplicações práticas" que constavam no programa anterior foram retiradas, pois essa ênfase agora ficava clara no texto introdutório. Pode-se considerar que essa orientação tenha sido decorrente da proposição de um "novo ensino médio", definido na Lei de Diretrizes e Bases da Educação Nacional n.9394/96, e cujas características principais foram delineadas nos Parâmetros Curriculares Nacionais para o Ensino Médio (PCNEM) (Brasil, 1999). Esses documentos definiram uma nova identidade para o Ensino Médio, que fora se perdendo ao longo da década de $1970 \mathrm{com}$ a não concretização das diretrizes que determinavam o caráter profissionalizante dessa etapa do ensino. Após a revogação da obrigatoriedade do Ensino Médio profissionalizante, pela Lei n.7044/82, houve uma perda de identidade desse nível de ensino, que em geral passou a ser visto apenas como uma etapa preparatória para o ingresso no ensino superior. A LDBEN e os PCNEM vieram definir o Ensino Médio como parte da educação básica, vinculada à prática social, possibilitando fundamentalmente uma formação voltada ao exercício da cidadania e ao fornecimento dos meios para futura inserção no mercado de trabalho e prosseguimento nos estudos posteriores. A menção à tomada de decisões e formação cidadã, inserida no programa de química do vestibular Fuvest 2002, reflete claramente essa orientação.

A experimentação ganhou um parágrafo explicativo próprio no texto introdutório ao programa de química, conferindo maior destaque a esse aspecto do que nas versões anteriores:

A experimentação, tanto a realizada em âmbito estrito de laboratório, como a realizada de maneira menos formal, mas sistematizada, no cotidiano, constitui aspecto fundamental do aprendizado da Química. Assim sendo, todos os itens do programa poderão envolver experimentação científica. (grifo nosso)

Observa-se, nesse trecho, um entendimento amplo a respeito da experimentação, abrangendo tanto práticas de laboratório quanto atividades realizadas fora dele. Em seguida, se explica o que se pretende avaliar em termos de habilidades relacionadas à experimentação: 
Espera-se que o candidato tenha habilidades específicas, tais como registrar e analisar dados, organizá-los em tabelas e gráficos, reconhecer a finalidade de materiais de laboratório em montagens experimentais, propor materiais adequados para a realização de experimentos, além do conhecimento de aparelhagens de laboratório usadas em operações básicas como filtração, destilação e titulação.

Por um lado, o programa faz referência a habilidades que podem ser desenvolvidas no contexto escolar fora do ambiente de um laboratório (por exemplo, por meio de observações sistemáticas realizadas em casa ou na sala de aula, com materiais alternativos). Por outro, ao exigir conhecimento de materiais de laboratório e da construção de aparelhagens para determinadas operações, o programa sinaliza a necessidade de que o candidato tenha vivência em um laboratório minimamente equipado - o que não corresponde à realidade que muitas escolas oferecem a seus alunos, podendo-se constituir em um obstáculo para os candidatos oriundos dessas escolas. Também é interessante observar que muitos professores defendem o ensino tradicional justificando a necessidade de cobrir todo o programa do vestibular (ver, por exemplo, Leal e Mortimer, 2008, p.224-5) - mas o mesmo argumento não tem sido utilizado para defender a inclusão de atividades experimentais ou de laboratórios em condições de funcionamento nas escolas. Um exemplo de questão (retirada da prova do segundo dia da segunda fase do Vestibular Fuvest 2012, cujo programa manteve as referidas recomendações sobre a experimentação) em que se avalia uma habilidade relacionada ao planejamento de um experimento é o seguinte:

O experimento descrito a seguir foi planejado com o objetivo de demonstrar a influência da luz no processo de fotossíntese. Em dois tubos iguais, colocou-se o mesmo volume de água saturada com gás carbônico e, em cada um, um espécime de uma mesma planta aquática. Os dois tubos foram fechados com rolhas. Um dos tubos foi recoberto com papel alumínio e ambos foram expostos à luz produzida por uma lâmpada fluorescente (que não produz calor).

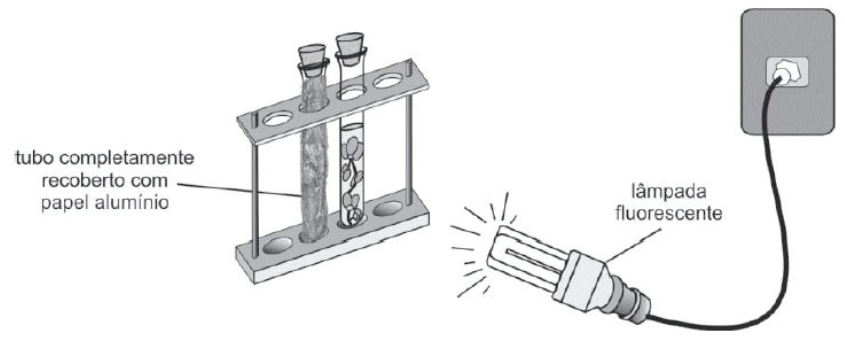

a) Uma solução aquosa saturada com gás carbônico é ácida. Como deve variar o pH da solução no tubo não recoberto com papel alumínio, à medida que a planta realiza fotossíntese? Justifique sua resposta.

No tubo recoberto com papel alumínio, não se observou variação de pH durante o experimento.

b) Em termos de planejamento experimental, explique por que é necessário utilizar o tubo recoberto com papel alumínio, o qual evita que um dos espécimes receba luz.

Observa-se que, para responder o item b dessa questão, o candidato necessita estar familiarizado com o conceito de controle de variáveis, ou seja, o isolamento de uma variável (no caso, a luz), mantendo todas as outras iguais, para investigar sua influência sobre um fenômeno. 
O discurso da aprendizagem de habilidades, presente nos PCNEM (Brasil, 1999), foi introduzido no programa, o que pode ser observado no trecho citado acima, a respeito da experimentação, e também na seguinte passagem, reformulada em relação ao texto anteriormente vigente: "As questões formuladas no vestibular conterão todos os dados necessários e avaliarão, principalmente, habilidades de compreensão, interpretação e análise das informações recebidas" (grifo nosso).

O texto introdutório ao programa de química de 2002 também deixou de fazer referência à história da ciência e, no corpo do programa, o item "histórico da radioatividade" foi omitido. Porém, a nova redação do item 1 , "Transformações químicas" traz como um de seus subitens "Evolução do modelo atômico: do modelo corpuscular de Dalton ao modelo de Rutherford-Bohr". A ideia de "evolução" do modelo não aparecia explicitamente nos programas anteriores, e nessa versão se apresenta como única remanescente da abordagem histórica valorizada como um dos pilares do tripé indicado para o ensino de química na Proposta Curricular do Estado de São Paulo em 1986 e incorporado ao programa do vestibular entre 1991e 2001.

O programa de 2002 reafirmou a exclusão dos modelos mais modernos para o átomo, detalhando, mais que no programa anterior, o que não seria abordado no vestibular: "não incluindo os modelos quânticos (orbitais atômicos, moleculares e hibridização)".

O programa manteve a estruturação anterior em sete itens, com os mesmos descritores - exceto para os itens 2 e 7 , cujos descritores foram simplificados, respectivamente, para "Propriedades e utilização dos materiais" e "Compostos orgânicos". O item que sofreu maior modificação foi o referente a "Transformações químicas", cuja organização deixou de acompanhar a sequência sugerida no livro Interações e Transformações. Também chama a atenção a alteração sofrida pelo item 7, no qual as características gerais e as reações orgânicas encontram-se agora em subitens separados da "química orgânica no cotidiano", e no programa anterior havia a preocupação de colocar lado a lado a fundamentação teórica e as aplicações práticas dos compostos orgânicos.

\section{Período III, Programa 6 (2003-2018)}

Esse período abrange o maior intervalo de vigência sem modificações de um programa de química para o vestibular. Em relação ao programa de 2002, a única modificação a partir de 2003 foi a introdução de pequenos textos antecedendo cada um dos sete itens principais da lista de conteúdos. Pode-se observar que a extensão e as ênfases de cada um desses textos são desiguais. $\mathrm{O}$ texto mais longo é o que apresenta o item "A água na Natureza”. Sua intenção é clara: destacar a importância da contextualização do conhecimento químico e seu papel na formação cidadã do estudante, relacionando-o a temas de interesse social. $\mathrm{O}$ seguinte trecho ilustra isso: 
O adensamento populacional e a expansão da atividade industrial vêm, de um lado, aumentando a demanda por água e, de outro, reduzindo sua oferta, este último fator ocorrendo em virtude da crescente poluição da água. Um tratamento mais sofisticado da água torna-se necessário e o tratamento de esgotos, imperativo. As propriedades da água, tais como sua capacidade de dissolver substâncias, seu calor de vaporização e seu calor específico, devem servir de base para o entendimento de sua importância na Terra e das medidas que podem ser tomadas para aumentar sua disponibilidade.

Outro texto que aponta nessa direção, ainda que de maneira bastante sucinta, é o que precede o item "Propriedades e utilização dos materiais": "Espera-se o conhecimento de algumas substâncias importantes na economia do País, em termos da ocorrência das matérias-primas, da produção industrial, das propriedades, da utilização e do descarte dessas substâncias". Em termos de conteúdos, chama a atenção na sequência desse mesmo texto o destaque dado às forças intermoleculares, um assunto que esteve ausente do programa do vestibular entre 1992 e 2001: "Interações intermoleculares precisam ser reconbecidas como determinantes de propriedades físicas de substâncias, tais como temperatura de ebulição e solubilidade" (grifo nosso). De fato, são conceitos importantes para a compreensão das relações entre os níveis submicroscópico e macroscópico da matéria, sendo curiosa sua ausência no Período II.

A contextualização é apresentada de maneira ainda mais tênue no item "Compostos orgânicos":

Os compostos orgânicos ocupam posição privilegiada na Química, não só pelo fato de constituírem a maioria dos compostos conhecidos, mas também por sua importância para a vida e presença em nosso cotidiano, na forma de uma variedade de materiais com que temos contacto (sic).

Considerando as possibilidades para abordagem de conteúdos de química orgânica, essa indicação soa bastante tímida. Nos outros quatro itens, porém, os conteúdos são apresentados de maneira descontextualizada, com a ênfase deslocada para o conhecimento em si mesmo. O seguinte trecho, do item "Energia nas transformações químicas", é ilustrativo: "é importante saber calcular a variação de entalpia numa transformação química a partir de entalpias de formação, entalpias de combustão ou de variações de entalpia em outras reações, bem como a partir de energias de ligação". Nesse trecho, como nos demais, se menciona a importância de saber conceitos ou fazer cálculos, sem qualquer justificativa de por quê são importantes, ou de quais aspectos da realidade são mais bem entendidos por meio desses conceitos. Vale destacar que esse item abrange também conteúdos como pilhas e eletrólise, que ensejam evidentes conexões com aspectos do cotidiano e do sistema produtivo. O texto mais sucinto é aquele que apresenta o item "Transformações nucleares naturais e artificiais", e praticamente apenas parafraseia a lista de conteúdos que o sucede. 
Nesse período, os enunciados das questões de química do vestibular tendem a ser mais longos, como consequência da tendência de fornecer alguma contextualização ao conhecimento que está sendo avaliado. A seguinte questão, presente no vestibular de 2013, exemplifica esses aspectos:
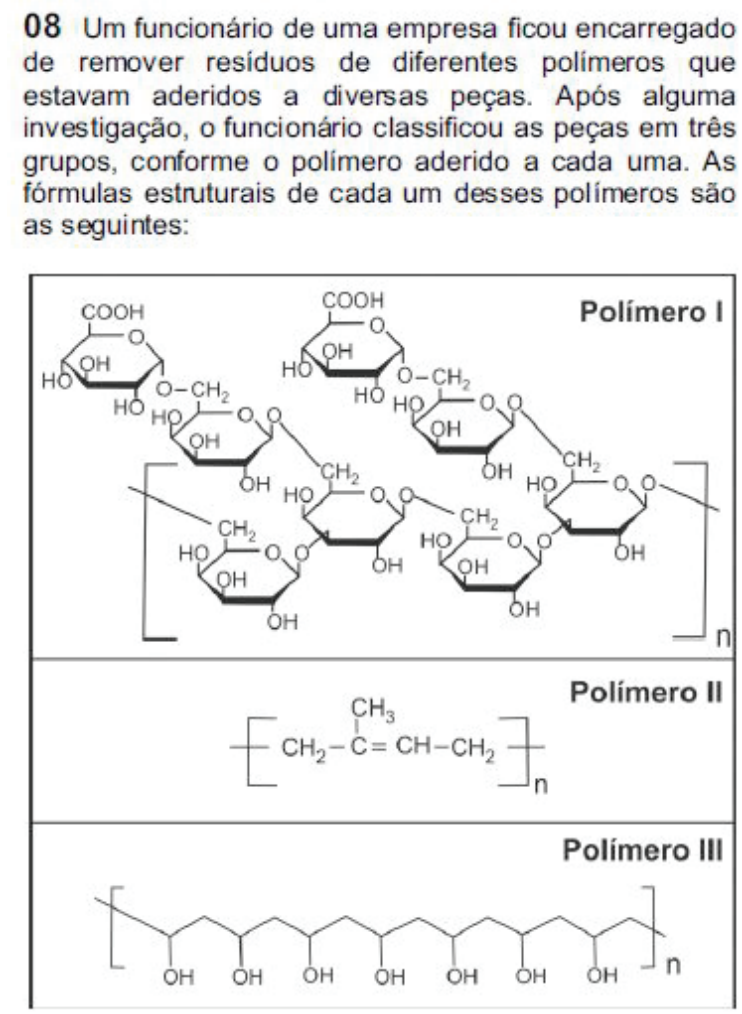

Para remover os resíduos de polímero das peças, o funcionário dispunha de apenas dois solventes: água e n-hexano. O funcionário analisou as fórmulas estruturais dos três polimeros e procurou fazer a correspondência entre cada polimero e o solvente mais adequado para solubilizá-lo. A alternativa que representa corretamente essa correspondência é:

\begin{tabular}{|c|c|c|c|}
\cline { 2 - 4 } \multicolumn{1}{c|}{} & Polimero I & Polimero II & Polimero III \\
\hline a) & água & n-hexano & água \\
\hline b) & n-hexano & água & n-hexano \\
\hline c) & n-hexano & água & água \\
\hline d) & água & água & n-hexano \\
\hline e) & água & n-hexano & n-hexano \\
\hline
\end{tabular}

A questão procura relacionar o conhecimento de estruturas moleculares e de conceitos como polaridade e ligações intermoleculares com um problema prático, associado à observação de um fenômeno macroscópico.

Nesse período, questões envolvendo a representação do modelo de partículas foram frequentemente propostas. Destacamos aqui uma questão apresentada no vestibular de 2003, na qual uma sucessão de quadros procura representar o aspecto dinâmico de uma transformação química: 
68 O esquema abaixo representa uma transformação química que ocorre na superfície de um catalisador.

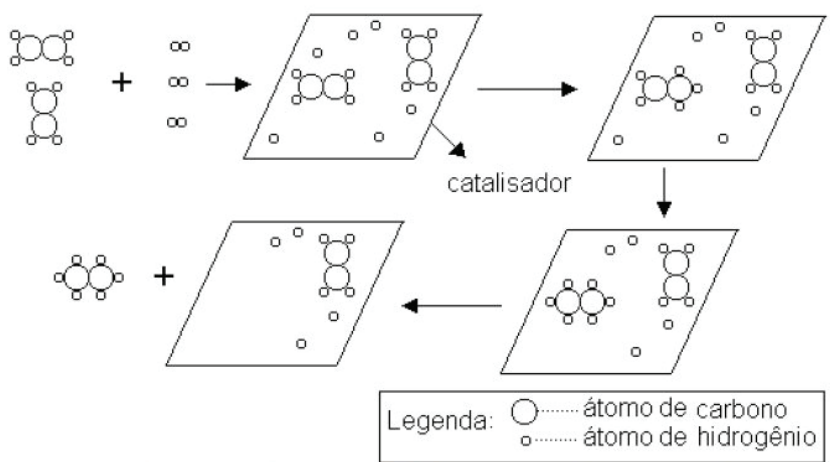

Uma transformação química análoga é utilizada industrialmente para a obtenção de
a) polietileno a partir de etileno.
b) celulose a partir de glicose.
c) peróxido de hidrogênio a partir de água.
d) margarina a partir de óleo vegetal.
e) naftaleno a partir de benzeno.

A sequência de imagens ilustra o processo de rompimento e formação de novas ligações químicas nas moléculas adsorvidas na superfície de um catalisador. Sua resolução requer a decodificação dessa representação, e a aplicação do conceito ilustrado (reação de hidrogenação catalítica) em outra situação (no caso, o processo industrial de produção de margarina).

Outra questão que se destaca por sua elaboração, proposta na segunda fase desse mesmo ano, também recorre à representação do modelo cinético de partículas, incluindo seu caráter dinâmico:

\footnotetext{
Uma mistura constituída de $45 \mathrm{~g}$ de cloreto de sódio e $100 \mathrm{~mL}$ de água, contida em um balão e inicialmente a $20^{\circ} \mathrm{C}$, foi submetida à destilação simples, sob pressão de $700 \mathrm{~mm} \mathrm{Hg}$, até que fossem recolhidos $50 \mathrm{~mL}$ de destilado.

O esquema abaixo representa o conteúdo do balão de destilação, antes do aquecimento:
}

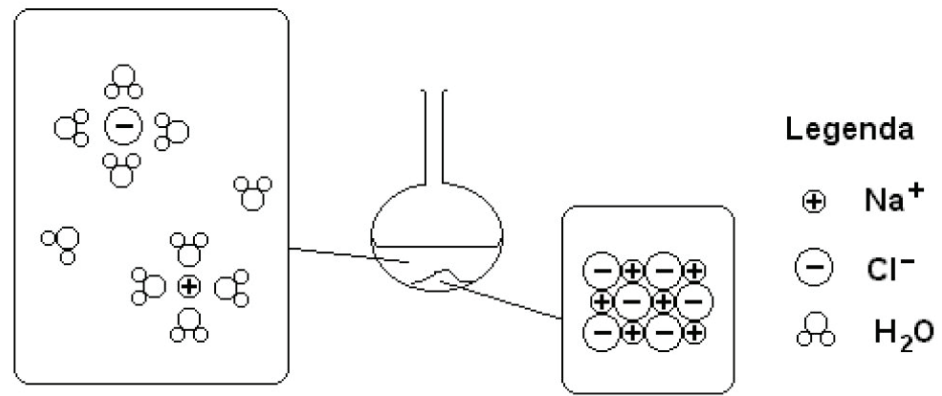

a) De forma análoga à mostrada acima, represente a fase de vapor, durante a ebulição.

Essa questão combina aspectos da experimentação, ao abranger a prática de destilação, com a representação das partículas submicroscópicas constituintes das substâncias envolvidas no processo. $\mathrm{O}$ item a, reproduzido aqui, requer que 
o candidato decodifique a representação e a reinterprete, propondo uma representação análoga para a fase de vapor resultante do aquecimento do sistema. Dessa forma, estão contemplados os aspectos dinâmicos e relacionais do processo: no interior do balão, coexiste o retículo cristalino do cloreto de sódio sólido e os íons dissociados e solvatados por moléculas de água; o candidato precisava representar a fase de vapor, no qual as moléculas de água estão afastadas entre si e não há íons. Nesse caso, a questão avalia a compreensão de aspectos fundamentais do conhecimento químico.

\section{Considerações finais}

Sendo de importância para a vida de milhares de jovens que, a cada ano, almejam o ingresso na Universidade de São Paulo, o Vestibular Fuvest opta por ser conservador, considerando que mudanças frequentes poderiam prejudicar o processo de preparação de seus candidatos. Esse caráter se manifesta também nos programas de química. Ao longo dos 39 anos analisados, houve apenas uma grande mudança do programa em 1991 (transição do Período I para o Período II) e outra, de menor extensão, em 2002 (transição do Período II para o Período III). As mudanças observadas são consequências das pesquisas e dos conhecimentos construídos na área de Ensino de Ciências, especialmente a partir da década de 1980, que encontraram manifestação também na Proposta Curricular para o Ensino de Química (São Paulo, 1986) e nos PCNEM (Brasil 1999). Uma futura alteração no programa de química do vestibular Fuvest talvez venha a se concretizar quando estiver em vigor a Base Nacional Comum Curricular, caso haja modificações relevantes em relação aos currículos atuais. Contudo, considerando o tumultuado processo que envolve a elaboração desse documento até a presente data, não há perspectiva de que essa alteração venha a ocorrer em breve.

As questões de química dos vestibulares Fuvest, por sua vez, se constituíram, ao longo do tempo, em um espaço dinâmico para a introdução gradual de diferentes formas de avaliação, a partir de novos objetivos delineados pelas tendências surgidas na área de ensino de ciências em geral, e de ensino de Química em particular. Decresceram as demandas por memorização de informações descontextualizadas; as questões de química passaram a ter enunciados mais longos, que requerem maiores habilidades de compreensão de texto; valorizou-se a interpretação de dados fornecidos na própria questão, na forma de gráficos, diagramas, arranjos experimentais etc., bem como a utilização de representações de partículas, em especial, para avaliar a compreensão a respeito das entidades submicroscópicas como modelos explicativos para os fenômenos macroscópicos. Assim sendo, considerando o vestibular como um dos fatores a contribuir para o complexo processo de construção curricular nas escolas, as transformações pelas quais o vestibular Fuvest passou nas últimas décadas sinalizaram tendências curriculares importantes, ao apontar para aspectos em sintonia com as pesquisas contemporâneas na área de ensino. Entretanto, as questões de vestibular se si- 
tuam em um limitado espaço de manobra: a necessidade de concisão, os limites impostos pelo formato de testes de múltipla escolha e, mais importante, a finalidade de se constituir em um exame de seleção (mais do que uma avaliação de aprendizagem) determinam restrições a seu alcance - e até mesmo podem gerar influências indesejadas no âmbito escolar. Cabe aos professores e professoras avaliar criticamente o vestibular e suas questões, em um necessário processo permanente de reflexão sobre os objetivos da educação básica e do ensino de sua própria disciplina.

Agradecimentos - O autor agradece ao Conselho Nacional de Desenvolvimento Científico e Tecnológico (CNPq) o auxílio à pesquisa (n.426519/2016) e a concessão de bolsa de produtividade em pesquisa (n.307652/2017-3).

\author{
Notas \\ I Disponível em: <http://acervo.fuvest.br/fuvest/>. \\ 2 Disponível em: <http://sotaodaquimica.com.br/crbst_3.html>.
}

\title{
Referências
}

BENNETT, J.; HOLMAN, J. Context based Approaches to the Teaching of Chemistry: what are they and what are their effects? In: GILBERT, J. K. et al. (Ed.) Chemical Education: Towards research based practice. Dordrecht: Kluwer Academic Press, 2002. p.165-84.

BERNAL, A.; DAZA, E. E. On the Epistemological and Ontological Status of Chemical Relations. Hyle - International Journal for Philosophy of Chemistry, v.16, n.2, p.80$103,2010$.

BOSQUILHA, G. E. et al. Interações e Transformações no Ensino de Química. Quimica Nova, v.15, n.4, p.355-71, 1992.

BRASIL - Ministério da Educação - Secretaria de Educação Média e Tecnológica. Parâmetros Curriculares Nacionais: Ensino Médio. Brasília: MEC/SEMTEC, 1999.

CHAMIZO, J. A. Technochemistry : One of the chemists' ways of knowing. Foundations of Chemistry, v.15, n.2, p.157-70, 2013.

GILBERT, J. K.; TREAGUST, D. Multiple Representations in Chemical Education. Dordrecht, Netherlands: Springer, 2010.

GOODSON, I. A construção social do currículo. Lisboa: Educa, 1997.

HOFFMANN, R. O mesmo e o não-mesmo. Trad. R. L. Ferreira. São Paulo: Editora Unesp, 2007.

JUSTI, R. Modelos e modelagem no ensino de química: um olhar sobre aspectos essenciais pouco discutidos. In: SANTOS, W. L. P.; MALDANER, O. A. (Org.) Ensino de Química em Foco. Ijuí: Editora Unijuí, 2010. p.209-30.

KNIGHT, D. Ideas in chemistry. New Brunswick, NJ (EUA): Rutgers University Press, 1992. 
LEAL, M. C.; MORTIMER, E. F. Apropriação do discurso de inovação curricular em química por professores do Ensino Médio: perspectivas e tensões. Ciência \& Educação, v.14, n.2, p.213-31, 2008.

SÃO PAULO (Estado) - Secretaria da Educação - Coordenadoria de Estudos e Normas Pedagógicas. Proposta curricular para o ensino de Química: $2^{\circ}$ grau. São Paulo: SE/CENP, 1986.

SCHUMMER, J. Scientometric studies on chemistry II: aims and methods of producing new chemical substances. Scientometrics, v.39, n.1, p.125-40, 1997.

. The Chemical Core of Chemistry I - A Conceptual Approach. Hyle - International Journal for Philosophy of Chemistry, v.4, p.129-62, 1998.

SILVA, R. R.; MACHADO, P. F. L.; TUNES, E. Experimentar sem medo de errar. In: SANTOS, W. L. P.; MALDANER, O. A. (Org.) Ensino de Química em Foco. Ijuí: Editora Unijuí, 2010. p.231-61.

SOUZA, K. A. F. D. Estratégias de comunicação em química como indices epistemológicos: análise semiótica das ilustrações presentes em livros didáticos ao longo do século $X X$. São Paulo, 2012. Tese (Doutorado em Química) -Instituto de Química, Universidade de São Paulo. São Paulo, 2012.

SOUSA, S. M. Z. L. Possíveis impactos das políticas de avaliação no currículo escolar. Cadernos de Pesquisa, n.119, p.175-90, jul. 2003.

TALANQUER, V. Macro, submicro and symbolic: the many faces of the chemistry “triplet”. International Journal of Science Education, v.33, n.2, p.179-95, 2011.

TOMASI, J. Towards "Chemical Congruence" of the Models in Theoretical Chemistry. Hyle - International Journal for Philosophy of Chemistry, v.5, n.2, p.79-115, 1999.

TONTINI, A. On the Limits of Chemical Knowledge. Hyle - International Journal for Philosophy of Chemistry, v.10, n.1, p.23-46, 2004.

TRINDLE, C. The Hierarchy of Models in Chemistry. Croatica Chemica Acta, v.57, n.6, p.1231-45, 1984.

RESUMO - Este artigo propõe uma análise de aspectos epistemológicos e didáticos dos programas e de algumas questões de química do vestibular Fuvest, referentes ao período de 1980 a 2018. A análise se volta para os critérios que orientaram a seleção e organização dos conteúdos; as relações sugeridas entre os níveis macroscópico e submicroscópico da matéria; o uso de modelos de partículas para explicação dessas relações; a experimentação e a contextualização do conhecimento químico. Observou-se uma grande mudança do programa em 1991 e outra, de menor extensão, em 2002, as quais podem ser relacionadas a mudanças em diretrizes curriculares estaduais e federais. $\mathrm{O}$ processo aqui delineado, de incorporação ao vestibular de tendências originadas na pesquisa em ensino de ciências, pode ensejar reflexões úteis aos educadores em química.

PALAVRAS-CHAVE: Vestibular, Ensino de Química, Fuvest, Avaliação.

ABSTRACT - This paper proposes an analysis of epistemological and didactic aspects of Chemistry programs and of some Chemistry questions of the University of São Paulo admission exam (Fuvest) from 1980 to 2018. Our analysis focuses on the criteria guiding the selection and organization of contents; on the implied relationships between 
the macroscopic and submicroscopic ontological levels of matter; on the use of particle models to explain such relationships; on experimentation and on the contextualization of chemical knowledge. There was a major change in the program in 1991 and a minor one in 2002, which may be related to changes in state and federal curriculum guidelines. The process outlined here, in which Science education research results influenced university admission exams, may lead to useful reflections for educators in chemistry. KErWORDS: University admission exam, Chemistry teaching, FUVEST, Evaluation.

Paulo Alves Porto é bacharel e licenciado em química pela Universidade de São Paulo, mestre e doutor em Comunicação e Semiótica pela PUC-SP, livre-docente na área de Ensino de Química pela USP, professor associado do Departamento de Química Fundamental IQ-USP. @-palporto@iq.usp.br

Recebido em 24.9.2018 e aceito em 19.10.2018.

I Instituto de Química, Universidade de São Paulo, São Paulo, São Paulo, Brasil. 
